\title{
I. Inhaltsverzeidnnis.
}

(I = Reidsteil; $\Pi=$ Randesteil.)

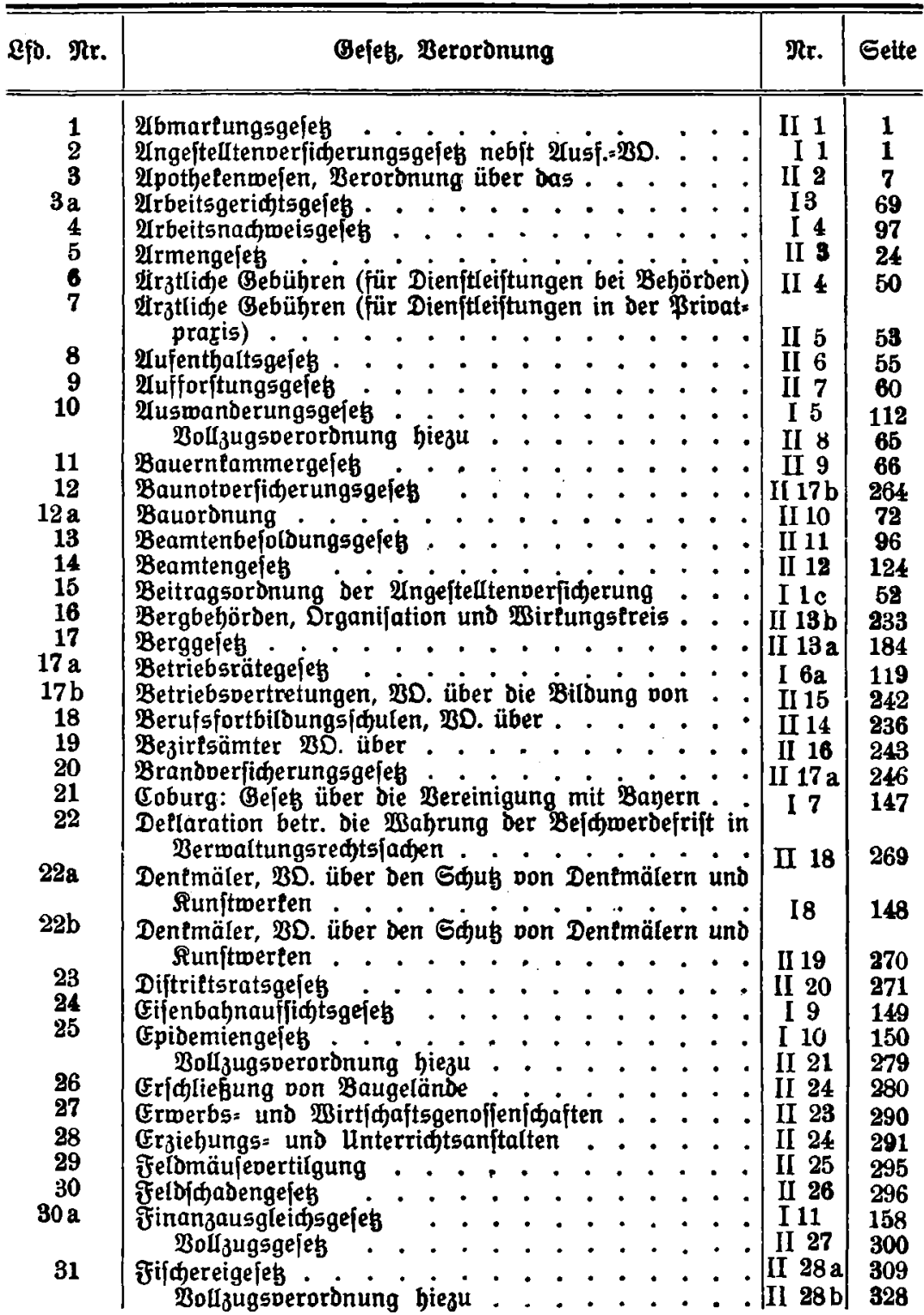




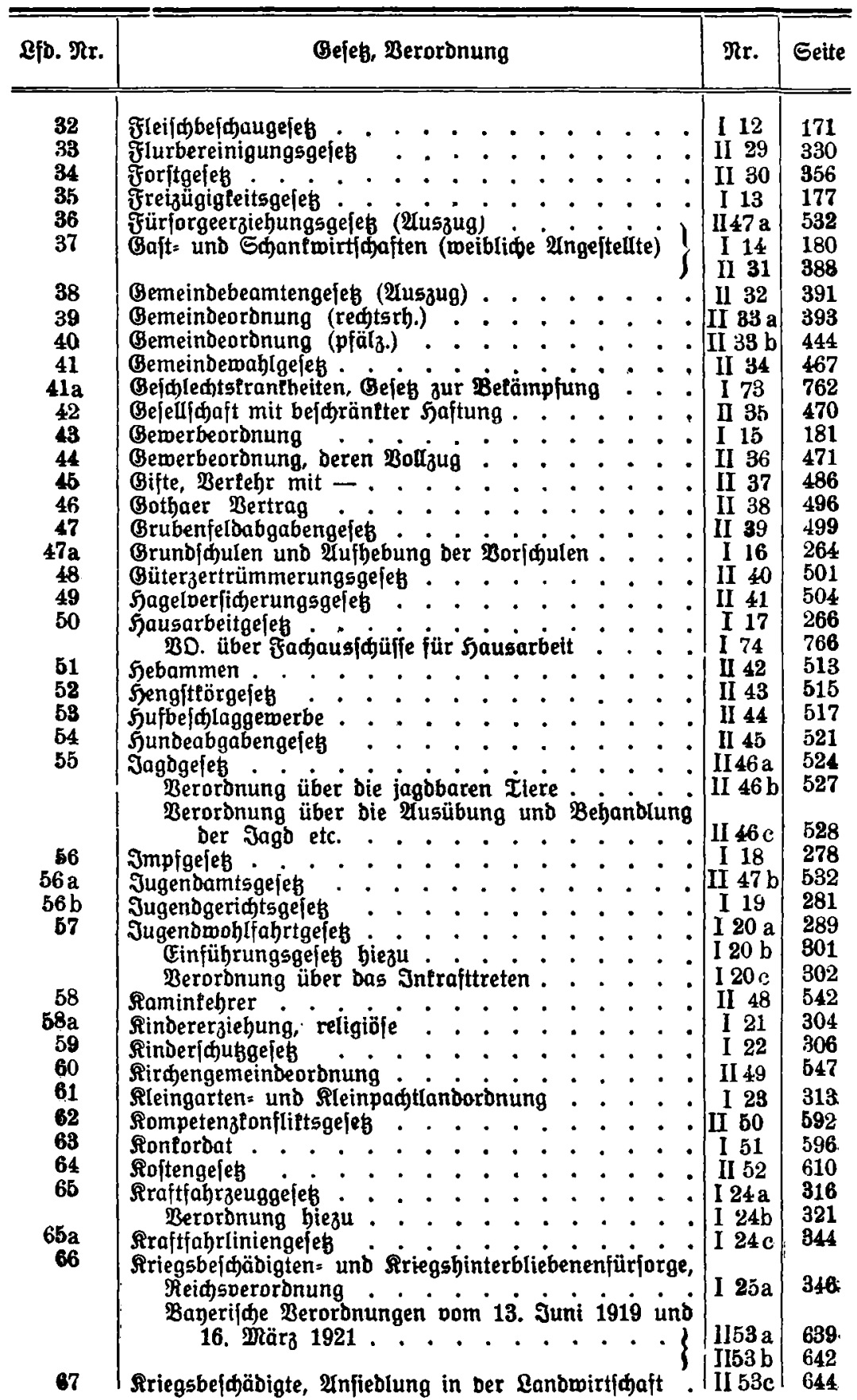


I. Inthaltsperzeidnis.

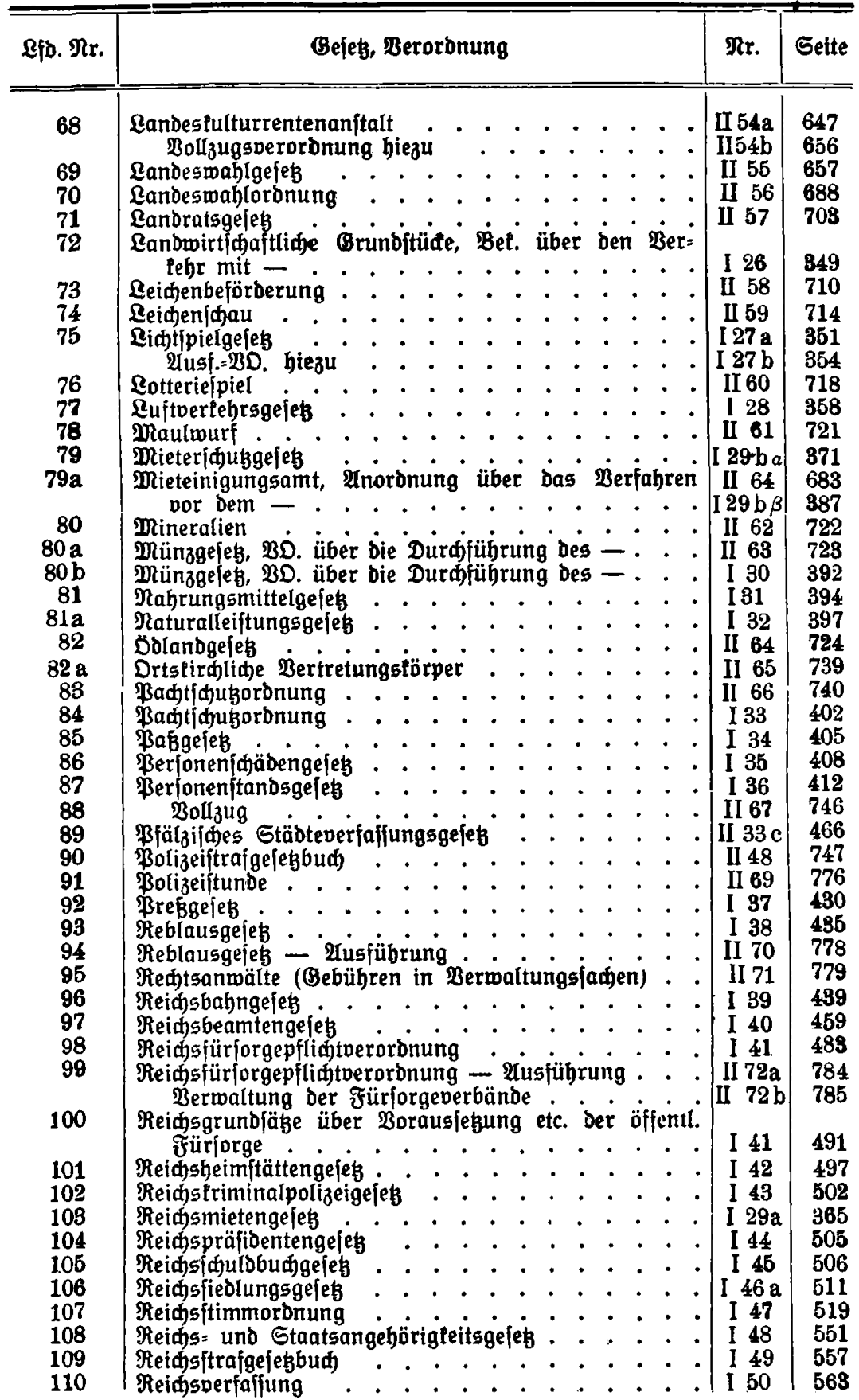




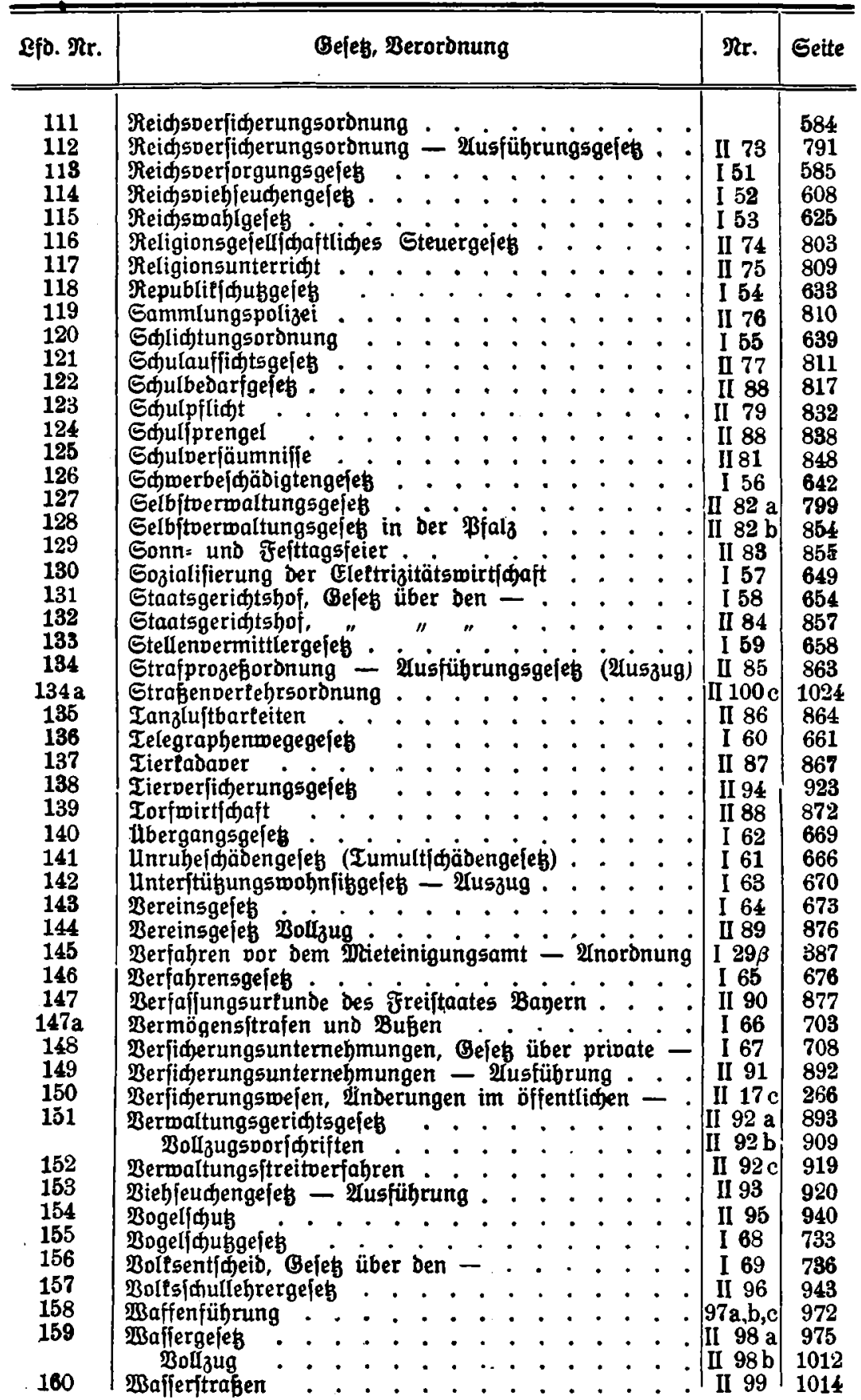


I. Inhaltsverzeidnis.

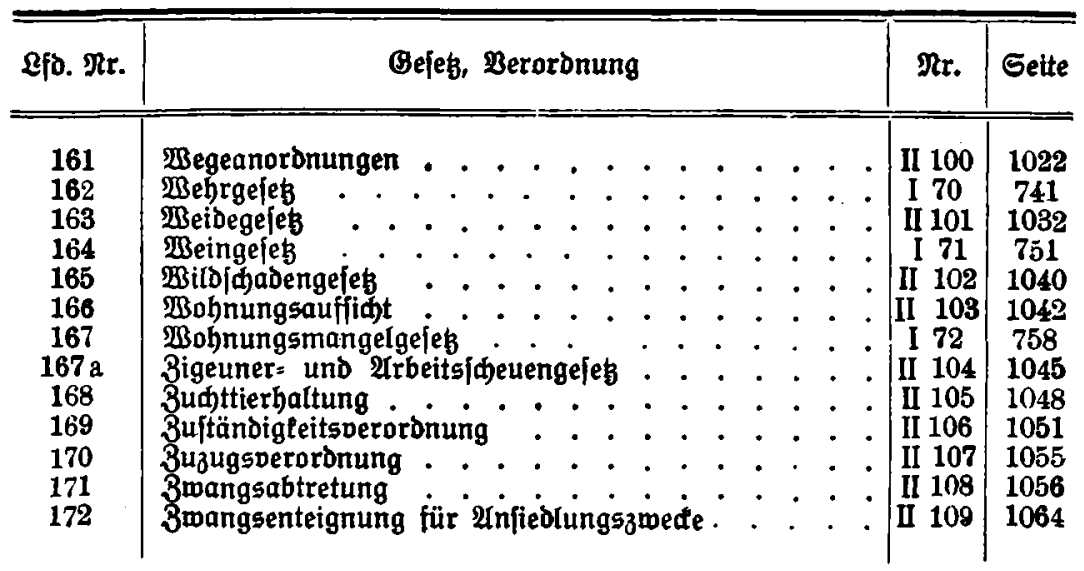

